just concluded a series of meetings in l'aris. The meeting was called to discuss Unesco's role in promoting international co-operation for oceanic exploration and was attended by consultants from scientific organizations in Australia, Denmark, Finland, France, tho German Federal Republic, Italy, the Netherlands, Norway, Poland, Sweden, the United Kingdom, the United States and the U.S.S.R. The ship, it was pointed out, would supplement research already being carried out on a national basis by some of the larger countries and could also tackle oceanographic problems that cannot be undertaken by the existing ships. To meet this task, it was suggested that the ship should be of about 1,200-1,300 tons and some $220 \mathrm{ft}$. long. Laboratory space would be provided for six permanent scientists and additional accommodation for fifteen visiting experts and students in training. A supplementary proposal recommended that Unesco should operate a number of chartered research ships on an international basis. Emphasizing the importance of increasing the food resources of the world by development of the oceans' potentialities, the consultants also urged that Unesco and the United Nations Food and Agriculture Organization should direct the attention of all governments to the importance of marine research. Further specific aid was requested from Unesco in the form of research contracts for individual workers and laboratories, fellowships for training purposes, travel allowances for scientists participating in international cooperative projects, the assignment of experts to countries requiring technical assistance in this field and the provision of equipment and facilities for co-operative projects between countries. These proposals are being submitted to the Director-General of Unesco for further exarmination.

\section{McGill University, Faculty of Engineering}

THe Faculty of Engineering of McGill University, in common with those of all other Canadian universities, is expecting a continuing growth in the number of applicants over the next decade, and is also anxious to encourage postgraduate studies to a greater extent than hitherto. The present buildings have been basically unchanged for some fifty years, although during that time, and particularly since 1945, relatively small additions have been made to accommodate the increased number of students admitted. In the session 1957-58 there was a total of some 1,800 undergraduate students in the Faculty, which represented the absolute maximum that the present buildings could take. In May 1958 ground was broken for a new engineering building to supplement the present facilities. This building, with an area of some $140,000 \mathrm{sq}$. ft., has been designed to provide lecture rooms and drafting rooms, particularly for the students in the earlier non-specialized years of the course ; to give, for the first time, proper quarters to the School of Architecture, and to provide completely new quarters for the Department of Electrical Engineering which was formerly housed in the old building. The release of this space from the old building will permit expansion of the Departments of Mechanical and Civil Engineering, where heavy installed equipment made it preferable to expand in situ rather than move into completely new quarters.

Mr. J. W. McConnell, the senior governor of the University, has made a magnificent gift which will cover the complete cost of this new building, which is expected to be opened in October 1959. The extra space then made available will make it possible for the faculty to embark upon a programme aimed primarily at the development of honours and graduate students in engineering, as well as permitting improvement in the quality of, and a small increase in the numbers admitted to, the ordinary engineering courses. The programme leading to the development of graduate work is already under way, and it is hoped soon to make appointments to three new chairs which have been created in control engineering, mining engineering and applied mechanies, and propulsion. It is also hoped that in the next few years a number of additional chairs will be created so that full use can be made of the new facilities.

\section{Higher Education in the United Kingdom}

THE revised edition of the handbook for students from overseas issued by the British Council and the Association of Universities of the British Commonwealth under the title "Higher Education in the United Kingdom" (pp. 208. London : Longmans, Green and Co., Ltd., 1958. 5s.) contains much useful information. Thus it includes, besides a dictionary of subjects and facilities for study and the lists of addresses of universities, technical colleges and other institutions, which occupy the greater part of the handbook, tables of fees and notes on the cost of study and residence, and on life in a British university or technical college. There is a foreword by Dr. R. S. Aitken, and a short article on universities in the United Kingdom by Sir James Mountford and another on technical education by Dr. P. F. R. Venables. The handbook brings together much information of great value not merely to overseas readers but also to those in Britain who are concerned with advising and placing students.

\section{British Commonwealth Collections of Micro- organisms}

THE United Kingdom National Committee of the British Commonwealth Collections of Micro-organisms is about to prepare a new edition of the "Directory of Collections and List of Species maintained in the United Kingdom and Crown Colonies". Directors of laboratories whose names appear in the 1951 edition will be asked to revise the information given in that directory, and to supply lists of microorganisms now available for distribution. Other laboratories may have established general or specialized culture collections since the 1951 Directory was prepared, and if they are willing to make their cultures available to other interested workers they are asked to send lists before December 31 to Dr. S. T. Cowan, Secretary of the U.K. National Committee, at the National Collection of Type Cultures, Central Public Health Laboratory, Colindale Avenue, London, N.W.9.

\section{Library Classification}

A scholarly address, "Library Classification and the Field of Knowledge", delivered by Mr. D. J. Foskett at the annual general meeting of the North Western Group of the Reference and Special Libraries Section by the Library Association in Manchester, on February 26, has been issued by the Association as Occasional Paper No. 1 (pp. 15. London: Library Association, 1958. 2s. 6d.). Systems of classification, Mr. Foskett shows, arise not empirically merely as a practical convenience but as reflexions of the state of scientific and philosophical thought in any age, 